\title{
Anti-mullerian hormone is expressed by endometriosis tissues and induces cell cycle arrest and apoptosis in endometriosis cells
}

\author{
Pietro G Signorile*, Francesca Petraglia and Alfonso Baldi
}

\begin{abstract}
Background: The anti-mullerian hormone (AMH) is a member of the transforming growth factor $\beta$ (TGF- $\beta$ ) superfamily, which is responsible of the regression of the mullerian duct. AMH is expressed in the normal endometrium, where, acting in a paracrine fashion, negatively regulates cellular viability. Our objective was to evaluate the in vitro effects of the treatment with $\mathrm{AMH}$ of endometriosic cells.

Methods: AMH expression in human endometriosis glands was evaluated by immunohistochemistry. RT-PCR has been used to quantify the expression levels of $\mathrm{AMH}$ and $\mathrm{AMH}$ Rll isoforms, as well as of cytochrome P450 in both endometriosis epithelial and stromal cells Effects of AMH and AMH-cleaved treatment in endometriosis cells were evaluated by flow-cytometry analysis. Finally, it has been evaluated the effect of plasmin-digested AMH on cytochrome P450 activity.

Results: $\mathrm{AMH}$ and $\mathrm{AMH}$ RII isoforms, as well as cytochrome P450, were expressed in both endometriosis epithelial and stromal cells. Treatment of endometriosis stromal and epithelial cell growth with $\mathrm{AMH}$ was able to induce a decrease in the percentage of cells in S phase and increase percentage of cells in G1 and G2 phase; coherently, decreased cell viability and increased percentage of cells death fraction was observed. The plasmin-digested AMH was able to suppress most of the cytochrome P450 activity, causing an increase of pre-G1 phase and of apoptosis induction treating with plasmin-digested AMH in both cell lines, most marked in the epithelial cells.
\end{abstract}

Conclusions: The data produced suggest a possible use of AMH as therapeutic agents in endometriosis.

Keywords: Endometriosis, Immunohistochemistry, AMH, Apoptosis

\section{Background}

Endometriosis is a gynaecological disease defined by the histological presence of endometrial glands and stroma outside the uterine cavity. Most commonly, endometrial structures are implanted over visceral and peritoneal surfaces, but rarely also in the pericardium, pleura, and even brain [1]. The prevalence in the general female population is $6-10 \%$; in women with pain, infertility or both, the frequency increases to $35-60 \%$ [2]. Endometriosis is usually associated with infertility and pelvic pain such as chronic dysmenorrhea, intermestrual abdominal and pelvic pain, back pain, dysuria, dyschezia and dyspareunia [3]. Moreover, it is often associated with a decrease of ovarian reserve and reduction of ovarian volume [4]. Despite the fact that this disease is quite common among women, it is

\footnotetext{
*Correspondence: research@endometriosi.it; alfonsobaldi@tiscali.it Centro Italiano Endometriosi, Via Aurelia, 559, Rome 00165, Italy
}

frequently misdiagnosed, the pathogenesis is unknown and the diagnostic and therapeutic protocols are still not fully adequate $[1,3]$. Currently, none of the pathogenetic theories proposed, such as retrograde menstruation, coelomic metaplasia or staminal cells, has definitively been proved [1]. Interestingly, our research group has recently demonstrated the presence of endometrial implants outside the uterus in a significant number of female human fetuses, thus demonstrating that alterations in the fine-tuning of the primitive mullerian tube formation is one of the causes of endometriosis [5-9].

The anti-mullerian hormone (AMH) is a homodimeric glycoprotein member of the transforming growth factor $\beta$ (TGF- $\beta$ ) superfamily, which is secreted by Sertoli cells in the embryonic testes and is responsible of the regression of the mullerian duct [10]. In the female fetus ovarian granulosa cells begin to secrete low levels of AMH starting 
from the 32 week of gestation. Levels surge at the time of puberty to approximately $5-8 \mathrm{ng} / \mathrm{mL}$ but then gradually decline throughout reproductive life until they become undetectable by menopause. Therefore, AMH levels are considered good indicators of the ovarian reservoir [11]. Recent studies have demonstrated that $\mathrm{AMH}$, as well as AMHRII (one of its receptors), are expressed in the adult female also in the endometrium, where, probably, act in a paracrine fashion and that negatively regulates cellular viability in the endometrium [12].

Leaving from this background, we decided to deeply investigate the potential role of AMH in regulating cell viability and proliferation of endometriosis cells, taking advantage of an in vitro model of epithelial and stromal endometriosis cells, recently generated in our laboratory [13].

\section{Methods}

\section{Patients and tissue samples}

Retrospective evaluation was performed on surgical specimens from 30 patients who underwent surgery for infertility, pelvic pain symptoms (including dysmenorrhea, deep dyspareunia and no-menstrual pain) or adnexal masses between 2009 and 2012 at the "Centro Italiano Endometriosi" in Rome and that were diagnosed with deep infiltrating endometriosis. Representative sections of each specimen were stained with haematoxylin-eosin to confirm the diagnosis of endometriosis. For immunohistochemistry 5$7 \mu \mathrm{m}$ specimen sections embedded in paraffin, were cut, mounted on glass and dried overnight at $37^{\circ} \mathrm{C}$. All sections were then deparaffinized in xylene, rehydrated through a graded alcohol series and washed in phosphate-buffered saline (PBS). PBS was used for all subsequent washes and for antiserum dilution. Tissue sections were quenched sequentially in 3\% hydrogen peroxide in aqueous solution and blocked with PBS-6\% non-fat dry milk (Biorad, Hercules, CA, U.S.A.) for $1 \mathrm{~h}$ at room temperature. Slides were then incubated at $4{ }^{\circ} \mathrm{C}$ overnight at 1:100 dilution with a rabbit polyclonal antibody for AMH (Abcam, Cambridge, UK). After three washes in PBS to remove the excess of antiserum, the slides were incubated with diluted goat anti-rabbit biotinylated antibody (Vector Laboratories, Burlingame, CA, U.S.A.) at 1:200 dilution in PBS-3\% nonfat dry milk (Biorad) for $1 \mathrm{~h}$. All the slides were then processed by the $A B C$ method (Vector Laboratories) for $30 \mathrm{~min}$ at room temperature. Diaminobenzidine (Vector Laboratories) was used as the final chromogen and hematoxylin was used as the nuclear counterstain. Negative controls for each tissue section were prepared by leaving out the primary antiserum. All samples were processed under the same conditions. Experiments were performed in compliance with the Helsinki Declaration and the protocols were approved by the ethics committee of the Fondazione Italiana Endometriosi.

\section{Cell lines and primary cells}

Human endometriosis stromal and epithelial cells were described elsewhere [13]. Cells were grown following standard procedures and were propagated in DMEM/ F12 (1:1) with 10\% Fetal Bovine Serum (FBS) (Gibco, Life Technologies Italia, Monza, Italy), 2 mM L-Glutamine (Euroclone S.p.a, Piero, Italy) and antibiotics $(100 \mathrm{U} / \mathrm{mL}$ penicillin, $100 \mu \mathrm{g} / \mathrm{mL}$ streptomycin and $250 \mathrm{ng} / \mathrm{mL}$ amphotericin-B).

\section{In vitro treatment with $\mathrm{AMH}$}

Cultured human endometrial stromal and epithelial cells were treated with Recombinant Human MullerianInhibiting Substance (rhMIS)/anti-Mullerian hormone (AMH) - E-Coli derived (R\&D Systems) and Purified recombinant protein of Homo sapiens AMH (OriGene Technologies, Rockville, MD, USA) at three different final concentrations (10-100-1000 ng) for three different time (24-48-72 hrs). Plasmin-cleaved AMH was used instead of the full-length molecule for incubation times indicated. AMH was digested by Plasmin from human plasma (Sigma-Aldrich, Italia) $1 \mathrm{~h}$ at $37^{\circ} \mathrm{C}$ in a ratio of 25 to 1, as described [14]. The effect of AMH on the activity of cytochrome P450 aromatase (CYP19) was measured through the P450-Glo assays (Promega Italia, Milano, Italy) [15].

\section{Cell vitality}

Experiments were performed in duplicate. Cells were diluted 1:1 in Trypan blue (Sigma-Aldrich, Italia) and counted.

\section{Cell cycle and cell death}

Analysis was performed in duplicate. 100.000 cells were re-suspended in the staining solution containing RNAse A, Propidium Iodide (PI) $(50 \mathrm{mg} / \mathrm{mL})$, sodium citrate (0.1\%), and NP40 (0.1\%) in PBS 1X for $30 \mathrm{~min}$ in the dark and room temperature. Cell cycle distribution was assessed with an FACScalibur flow cytometer (Becton Dickinson), and 10,000 cells were analyzed by ModFit version 3 Technology (Verity) and Cell Quest (Becton Dickinson) [16].

\section{RNA, RT-PCR}

Total RNA was extracted with TRIzol (Life Technologies) and converted into cDNA using SuperScript VILO kit according to the manufacturer's protocol. (Invitrogen). Converted cDNA was amplified using EuroTaq (Euroclone). Amplified DNA fragments were loaded on 2.0\% agarose gel and photographed on a Gel Logic 200 Imaging system UV transilluminator (Kodak). Levels of AMH, AMH type II Receptor (AMHR-II) and CYP19 expression were quantified by Reverse Transcription Polymerase Chain Reaction (RT- 


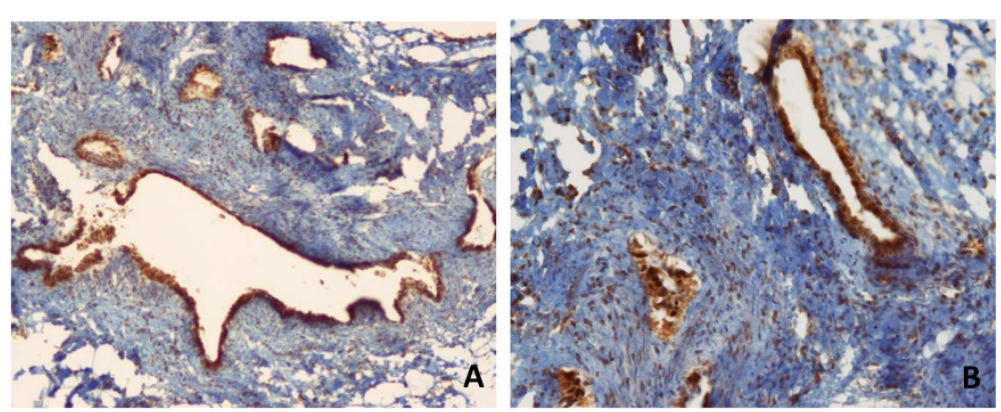

Figure 1 Immunohistochemical expression of AMH in endometriosis tissues. (A) AMH expression in the epithelium of an endometriosis gland (Original magnification X20). (B) The immunohistochemical expression of AMH is clearly visible also in the stromal cells of the endometriosis gland (Original magnification X20).

PCR). Real-Time PCR was performed using iQ SYBR Green Supermix (Bio-Rad) in a DNA Engine Opticon2 thermal cycler (MJ Research Incorporated). Primers: AMH gene (1) (Forward 5'-CAC CCG CTA CCT GGT GTT AG-3', Reverse 5'-GGT CAT CCG TGT GAA GCA G-3'). AMH gene (2) (Forward 5'-AAG CTG CTC ATC AGC CTG TC-3', Reverse 5' -TGG GGT CCG AAT AAA TAT GG3'). AMHR-II gene (1) (Forward 5'-CCC TGC TAC AGC GAA AGA AC-3', Reverse 5'-ATG GCA ACC AGT TTT CCT TG-3'). AMHR-II gene (2) (Forward 5'-AAC TGG
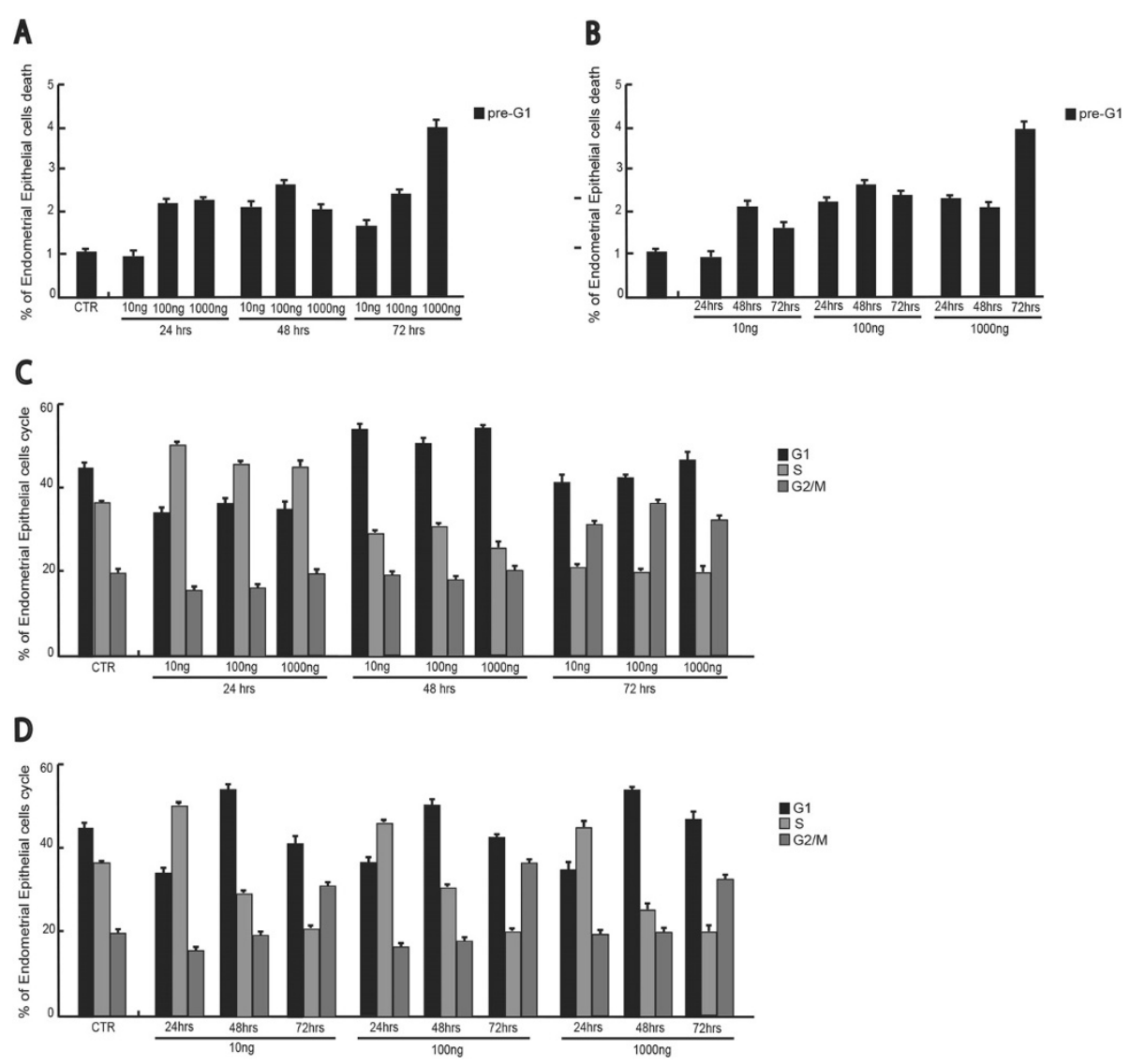

Figure 2 Effects of recombinant human Mullerian-inhibiting substance (MIS)/anti-Mullerian hormone (E.Coli derived) on endometriosis epithelial cell line. (A) pre-G1 fraction analysis of endometriosis epithelial cells treated for 24-48-72 hrs with the indicated final concentrations of MIS. The data are shown in a time-dependent manner. (B) pre-G1 fraction analysis of endometriosis epithelial cell line treated for 24-48-72 hrs with the indicated final concentrations of MIS. The data are shown in a dose-dependent manner. (C) Cell cycle analysis of endometriosis epithelial cells treated 24-48-72 hrs with the indicated final concentrations of MIS. The data are shown in a time-dependent manner. (D) Cell cycle analysis of endometriosis epithelial cells treated 24-48-72 hrs with the indicated final concentrations of MIS. The data are shown in a dose-dependent manner. 


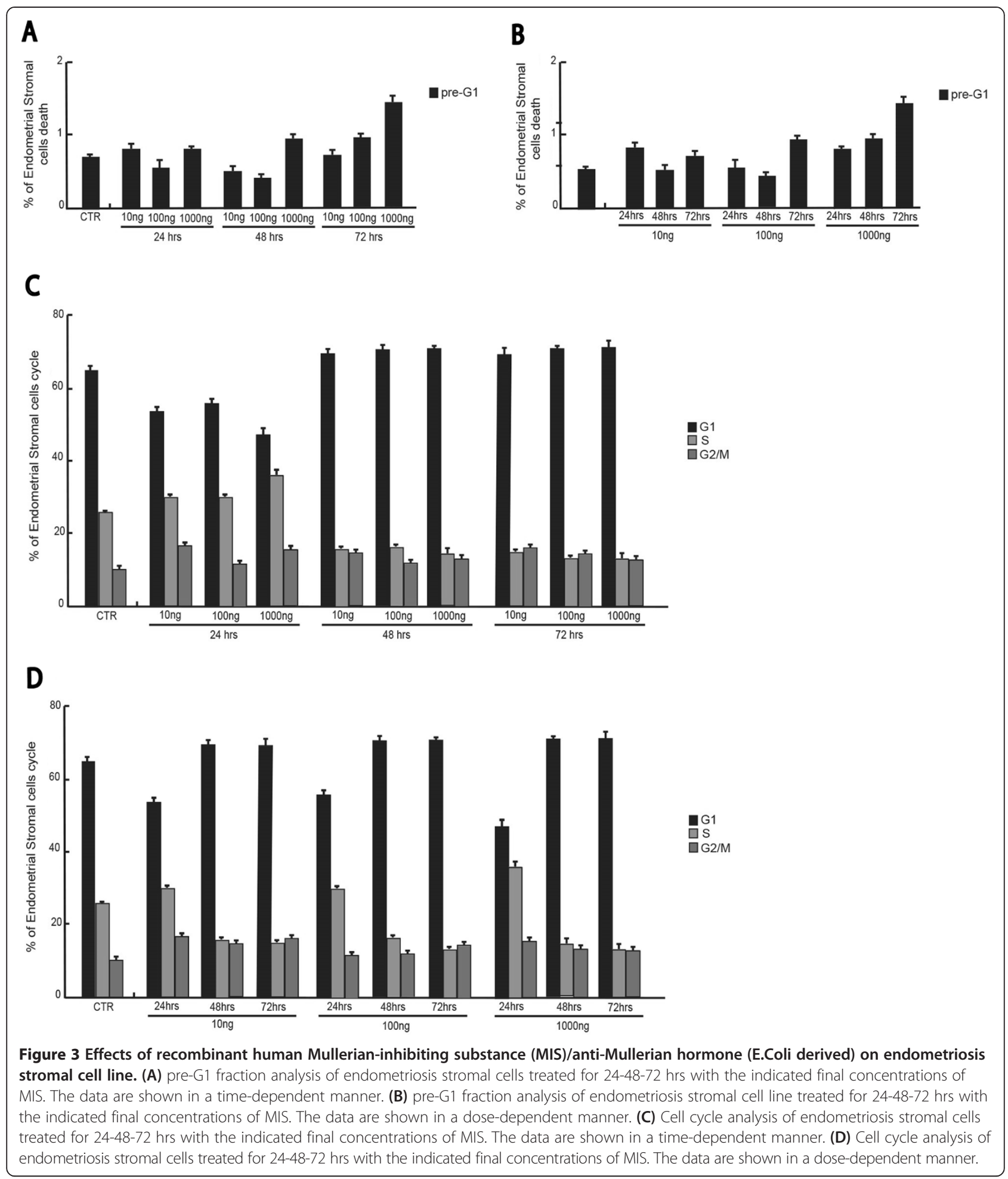

CCT ATG AGG CAG AA-3', Reverse 5'-GGT CTG CAT CCC AAC AGT CT-3'). GAPDH gene (Forward 5'-GGA GTC AAC GGA TTT GGT CGT-3', Reverse 5'-GCT TCC CGT TCT CAG CCT TGA-3').

\section{Results}

Histologic examination of endometriosis lesions of the rectovaginal septum showed the typical presence of both endometriotic glands and stroma. Immunohistochemical 
staining demonstrated that both epithelial and stromal component expressed significant levels of AMH. Figure 1 depicts some exemplary cases of the immunohistochemical staining for $\mathrm{AMH}$ in cases of endometriosis of the rectovaginal septum.

We were able to demonstrate the effects induced by Recombinant Human Mullerian-Inhibiting Substance (rhMIS)/anti-Mullerian hormone (AMH)E. Coli derived on endometriosis stromal and epithelial cell growth, cell cycle progression and apoptosis induction. We have treated cultured human endometriosis stromal and epithelial cells with rhMIS at different concentrations (10-100-1000 $\mathrm{ng} / \mathrm{mL})$ and analyzed the effects induced after 24-48-72 hours of treatment.

To investigate the various phases of the cell cycle, the Flow Cytometer FACS (Fluorescent Activated Cell Sorter) was used. The results shown were obtained using the Cell Quest software (Becton Dickinson) and are shown in a dose and time dependent manner to better visualize the effect induced by treatment (Figure 2). As depicted in Figure $2 \mathrm{~A}$ and $\mathrm{B}$, induction of cell death was present upon treatment in a time and dose dependent manner. Despite weak, this apoptotic effect was fully reproducible and specifically connected to the hormone treatment. The changes in cell cycle distribution after 24 hours of AMH exposure suggested that AMH plays an important role in inducing an initial increase in the percentage of cells in the $S$ phase, which is translated into a G1 block at 48 hrs. Interestingly, while the effects on apoptosis are dose and time dependent, the cell cycle effects seem only time dependent (Figure 2C-D). The results of high-AMH concentrations treatment have confirmed a decreased percentage of cells in $S$ phase with increased percentage of cells in G1 and G2 phase (Figure 2D) and increasing local AMH concentration in cultured human endometriosis stromal cells decreased cell viability and increased percentage of cells death fraction also (Figure 2A-B).

These effects where fully confirmed by using the stromal cells (Figure 3). Despite slightly more resistant, in these cells the apoptosis induced by the hormone was time and dose dependent, whereas the cell cycle effects were only time dependent.

Similarly, the Purified recombinant protein of Homo sapiens AMH treatment (10-100-1000 ng for 24-48-72 hours) on endometriosis stromal cells line resulted in coherent results (Figure 4A-B). A small decrease in percentage of cells in $S$ and $G 2 / M$ phases was observed (Figure $4 A$ ) with a concomitant increase of cells in pre-G1 phase (Figure $4 \mathrm{~B}$ ).

Various semi-quantitative RT-PCR have been used to quantify the expression levels of $\mathrm{AMH}$ and $\mathrm{AMH}$ RII isoforms in both endometriosis epithelial and stromal cells (Figure 5A). The two isoforms analyzed were designed with the Primer3 software. Both endometriosis epithelial and stromal cells expressed mRNA for AMH and AMH RII (Figure 5A). Finally, the expression levels of CYP19 were confirmed through real-time PCR analysis (Figure 5B).

Considering that the plasmin-digested $\mathrm{AMH}$ has been reported to be more active in cultured human endometrial cell lines [15], human plasmin was used to cleave and activate the recombinant Human $\mathrm{AMH}$ at its monobasic arginine-serine site at residues 427-428 and then tested in functional experiments on both endometriosis stromal and epithelial cells. Firstly, we found that plasmin-digested $\mathrm{AMH}$ can alter the expression or function of CYP19, evaluated by testing CYP19 activity. The results suggest that the plasmin-digested AMH was able to suppress most of the CYP19 activity. When the plasmin-digested AMH was used on both endometriosis stromal and epithelial cells (Figure 6), an increase of pre-G1 phase treating with
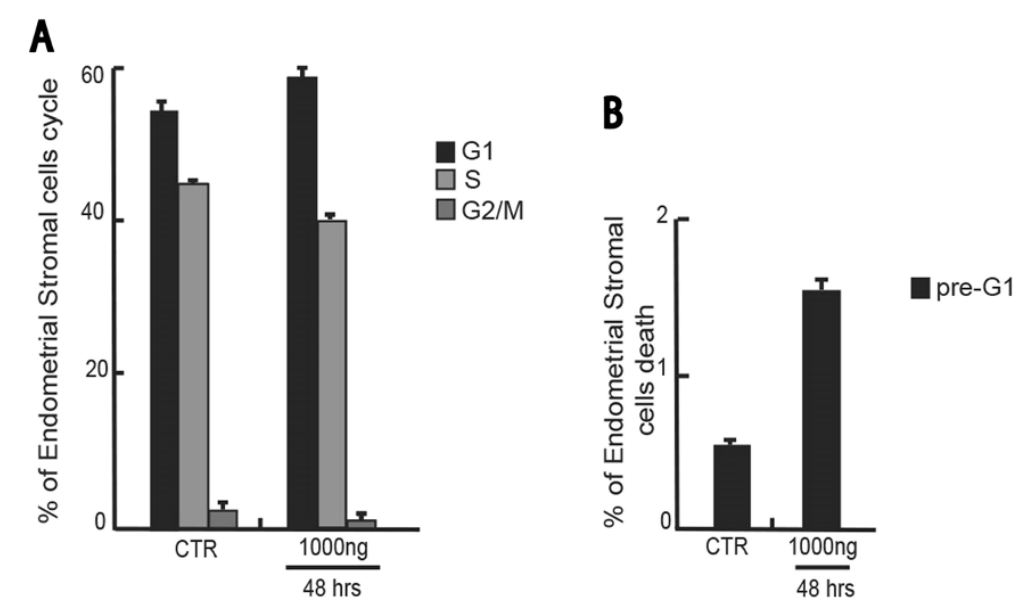

Figure 4 Effects of purified recombinant protein of Homo Sapiens anti-Mullerian hormone (AMH) on endometriosis stromal cell line. (A) Cell cycle analysis of endometriosis stromal cells treated for $48 \mathrm{hrs}$ with $\mathrm{AMH}$ at $1000 \mathrm{ng} / \mathrm{mL}$. (B) pre-G1 fraction analysis of endometriosis stromal cells treated for 48 hrs with $\mathrm{AMH}$ at $1000 \mathrm{ng} / \mathrm{mL}$. 


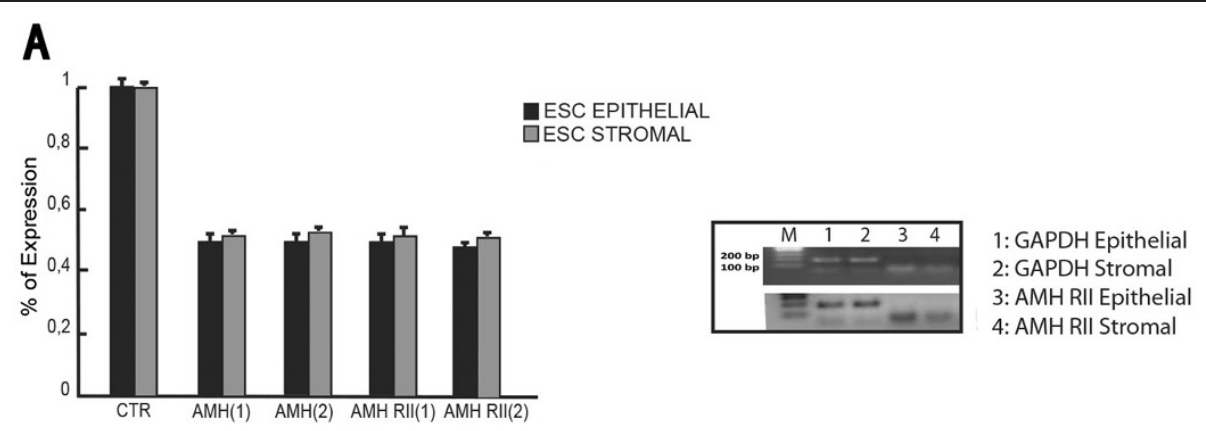

B Cyt P(450) Expression and Activity

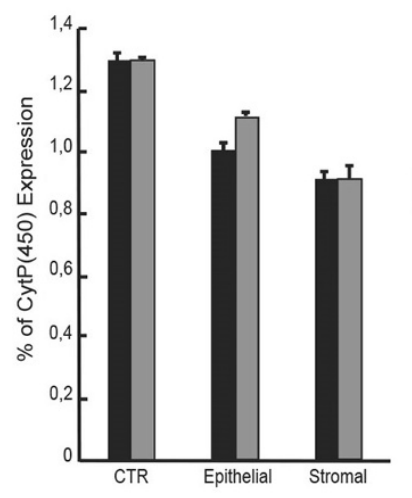

CytP $(450) 1$
$\square \operatorname{CytP}(450) 2$

C

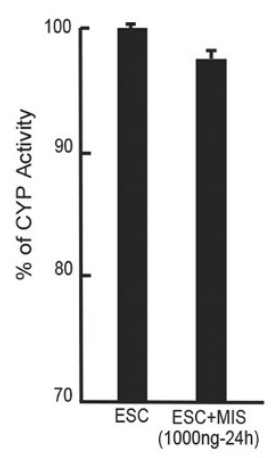

D

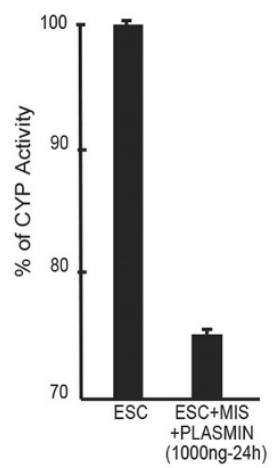

1: GAPDH Epithelial

2: CytP450 (1) Epithelial

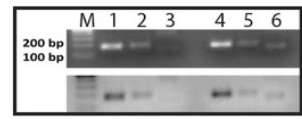

Epithelial

4: GAPDH Stromal

5: CytP450 (1) Stromal

6: CytP450 (2) Stromal

Figure 5 Analysis of AMH, AMHRII expression and CytP450 activity. (A) Real-time PCR to assess the percentage of expression levels of AMH (1), AMH (2), AMH type II Receptor (1) and (2) (AMH RII) genes in endometrial epithelial and stromal cell line respectively. (B) Expression levels of the Cytochrome P4501 and 2 isoforms and Reverse Transcriptase-Polymerase Chain Reaction (RT-PCR) for the CytP (450) 1 and 2 in epithelial and stromal cell line respectively; GAPDH represents loading control. (C) CYP Activity assay in endometrial stromal cells treated for $24 \mathrm{hrs}$ at $1000 \mathrm{ng} / \mathrm{mL}$ of MIS full-length. (D) CYP Activity assay in endometrial stromal cells treated for 24 hrs at $1000 \mathrm{ng} / \mathrm{mL}$ of Plasmin-cleaved MIS.

plasmin-digested AMH in both cell lines was detected, most marked in the epithelial cells (Figure 6). Also the effect on induction of apoptosis was stronger during the first 24 hours of treatment (Figure 6A-B). Interestingly, and differently from the previous experiments, apoptosis decreased after the 24 hrs, suggesting that, possibly, the cleaved AMH is more unstable than the full-length protein. These results are also supported by the cell cycle analysis which showed very weak effects on the stromal cells, only at $72 \mathrm{hrs}$ at the highest concentration (Figure 6E-F).

\section{Discussion}

Endometriosis is a benign disease of women during reproductive age [17]; nevertheless, it is well known that endometriosic cells display functional properties that are typical of neoplastic cells, such as anti-apoptotic, invasive and metastatic capacities $[18,19]$. In support to this observation, epidemiological studies have shown that there exists an increased risk of different types of malignancies, especially ovarian cancer and non-Hodgkin's lymphoma in women with endometriosis [20,21]. Nevertheless, it has 

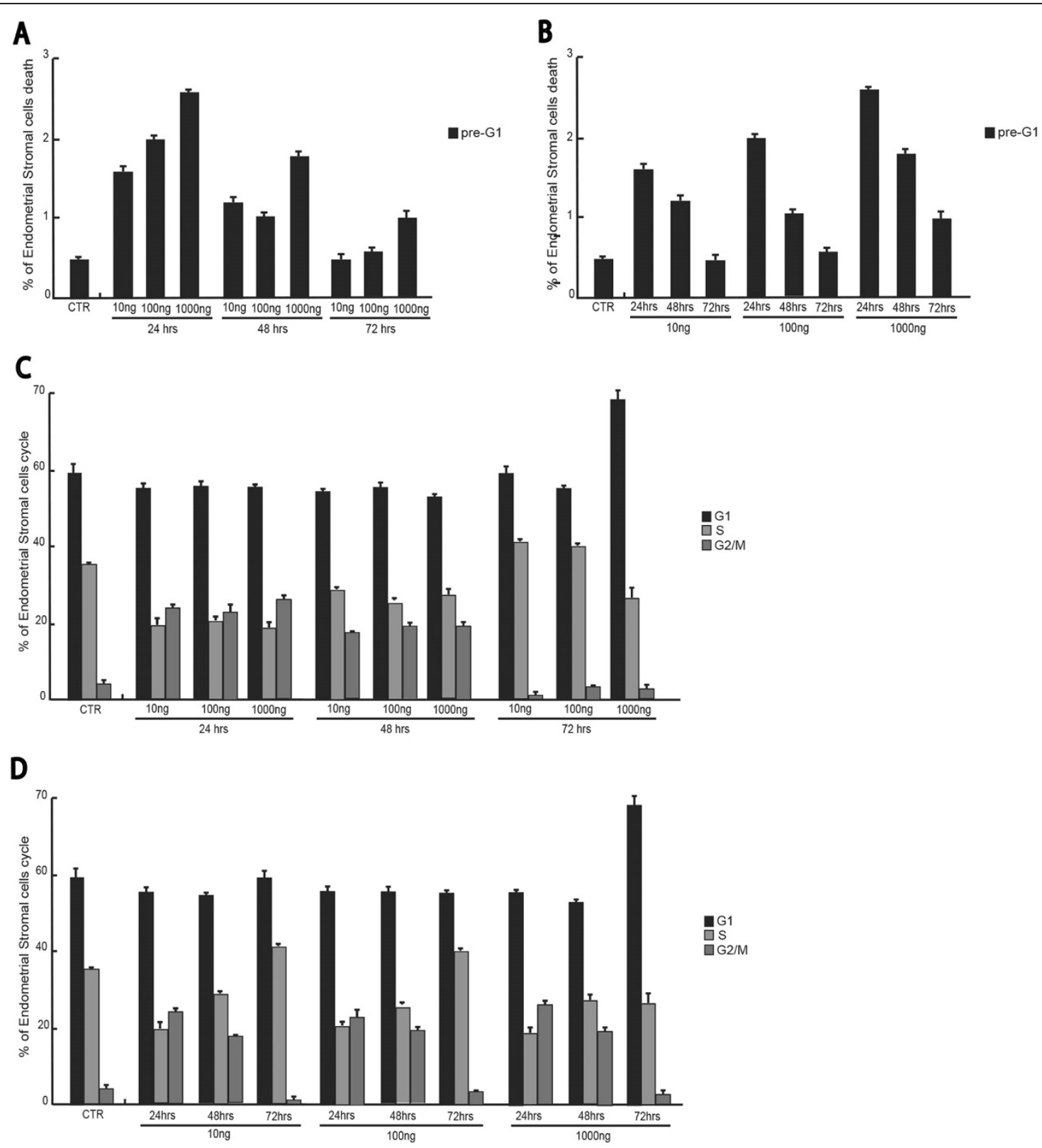

E

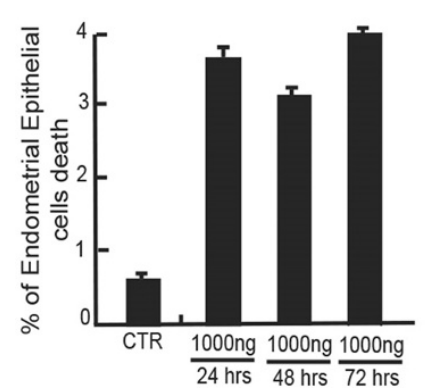

口pre-G1

F

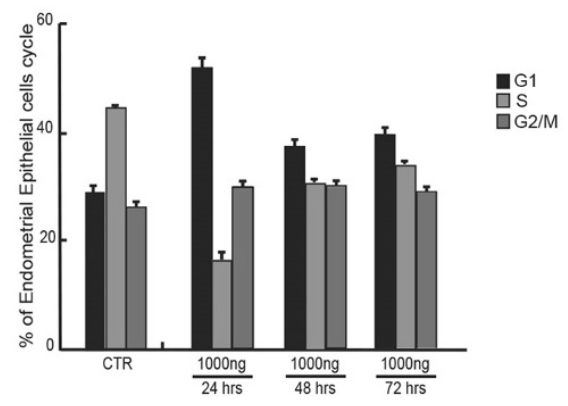

Figure 6 (See legend on next page.) 
(See figure on previous page.)

Figure 6 Effects of purified recombinant protein of Homo Sapiens anti-Mullerian hormone (AMH) digested by Plasmin from human plasma on endometriosis stromal and epithelial cell line. (A) pre-G1 fraction analysis of endometriosis stromal cells treated for 24-48-72 hrs with the final concentrations of cleaved MIS as indicated. The data are shown in a time-dependent manner. (B) pre-G1 fraction analysis of endometriosis stromal cells treated for 24-48-72 hrs with the final concentrations of cleaved MIS as indicated. The data are shown in a dose-dependent manner. (C) Cell cycle analysis of endometriosis stromal cells treated for 24-48-72 hrs with the final concentrations of cleaved MIS as indicated. The data are shown in a time-dependent manner. (D) Cell cycle analysis of endometriosis stromal cells treated for 24-48-72 hrs with the final concentrations of cleaved MIS as indicated. The data are shown in a dose-dependent manner. (E) pre-G1 fraction analysis of endometriosis epithelial cells treated for 24-48-72 hrs with 1000 ng/mLof cleaved MIS. The data are shown in a time-dependent manner. (F) Cell cycle analysis of endometriosis epithelial cells treated for 24-48-72 hrs with $1000 \mathrm{ng} / \mathrm{mL}$ of cleaved MIS. The data are shown in a time-dependent manner.

been reported an association between endometriosis, dysplastic nevi, melanoma, and breast cancer [22,23]. Finally, several histological and genetic studies have indicated that endometriosis may transform into cancer or that it could be considered a precursor of cancer [24]. Recently, it has been demonstrated by Wang et al., that adult human endometrium has a functional AMH/AMHRII signal transduction system and that the activation of this system is able to negatively regulate cellular viability in cultured endometrial cells [12]. Indeed, the exact biological role of $\mathrm{AMH}$ in adult females is unclear. The most well recognized function in adult is its involvement in recruitment and selection of initial primordial follicles [25]. In fact, there exists a plethora of research articles on the use of AMH serum level as a sensitive marker to assess the ovarian reserve [26]. However, consistently with the work by Wang et al. [12], several papers have shown a part for $\mathrm{AMH}$ as a regulator of cell growth in cells and tissues of Mullerian origins, such as endometrial, ovarian, cervical and breast tissues and a role for AMH as potential therapeutic factor in tumors originating from these tissues has been proposed [27-31]. Recently, two independent research groups have demonstrated that the AMH system is active also in endometriosic cells in vitro and that it acts as a negative regulator of cell cycle and cell viability $[32,33]$.

In this study we have shown that AMH protein is clearly expressed in endometriosis glands in humans; that it is also expressed together with its receptor AMH RII in our in vitro model of endometriosis; and that it is able to inhibit cell proliferation and to induce apoptosis in endometriosis cells, both epithelial and stromal. Several experimental studies have revealed that AMH is strongly activated by cleavage [34]. In fact, the C-terminal fragment contains the conserved TGF $\beta$ domain [35] and the cleavage is necessary for efficient receptor binding [36]. Consistent with these observation, it has been reported that the plasmin-digested AMH is more active in cultured human endometrial cell lines [15]. In our experimental setting, we have been able to demonstrate that cleaved AMH is effective in inhibiting cell proliferation in endometriosis cells. Moreover, this cleaved form of AMH is able to inhibit most of the CYP19 activity in endometriosis cells, as it has been already shown for cultured granulosa lutein cells [15]. Several studies have suggested that endometriosis implants are able to produce estrogen de novo from cholesterol [37]. Therefore, endogenous steroidogenic genes in local estradiol biosynthesis in endometriosis are crucial for the survival of these implants. Based on this rationale, it has been recently proposed the use of aromatase inhibitors as a novel treatment of endometriosis. Our experimental data demonstrate, indeed, that $\mathrm{AMH}$ treatment is able to inhibit CYP19 activity, that is the key enzyme in humans for the conversion of $\mathrm{C}_{19}$ steroids to estrogens [38], thus suggesting a possible biological explanation of the effects of this hormone on cell growth and apoptosis.

\section{Conclusions}

The clinical and therapeutic implications of this observation are straightforward. In fact, all current endometriosis treatments, including surgical and medical strategies, have high recurrence rates of up to $45 \%$ [17]. The data produced suggest a possible use of $\mathrm{AMH}$ as therapeutic agents in endometriosis. Additional functional studies both in vitro and in vivo are necessary in order to define applicable therapeutic modalities.

\section{Competing interests}

The authors declare that they have no competing interests.

\section{Authors' contributions}

PGS and $A B$ conducted the work, analyzed the data and wrote together the manuscript; FP performed the in vitro experiments. All authors read and approved the final manuscript.

Received: 18 April 2014 Accepted: 19 May 2014

Published: 29 May 2014

\section{References}

1. Bulun SE: Endometriosis. New Engl J Med 2009, 360:268-279.

2. Cramer DW, Missmer SA: The epidemiology of endometriosis. Ann N Y Acad Sci 2002, 955:11-22.

3. Baldi A, Campioni M, Signorile PG: Endometriosis: pathogenesis, diagnosis, therapy and association with cancer. Oncol Rep 2008, 19:843-846.

4. Signorile PG, Spugnini EP, Citro G, Viceconte R, Vincenzi B, Baldi F, Baldi A: Endocrine disruptors in utero cause ovarian damages linked to endometriosis. Front Biosci 2012, 4:1724-1730.

5. Signorile PG, Baldi F, Bussani R, D'Armiento $M$, De Falco M, Baldi A: Ectopic endometrium in human foetuses is a common event and sustains the theory of mullerianosis in the pathogenesis of endometriosis, a disease that predisposes to cancer. J Exp Clin Cancer Res 2009, 28:49.

6. Signorile PG, Baldi F, Bussani R, D'Armiento M, De Falco M, Boccellino M, Quagliuolo L, Baldi A: New evidences sustaining the presence of endometriosis in the human foetus. RBM online 2010, 21:142-147. 
7. Signorile $P G$, Baldi F, Bussani R, Viceconte R, Bulzomi P, D'Armiento M, D'Avino A, Baldi A: Embryologic origin of endometriosis: analysis of 101 human female foetuses. J Cell Physiol 2012, 227:1653-1656.

8. Signorile PG, Baldi A: Endometriosis: new concepts in the pathogenesis. Int J Biochem Cell Biol 2010, 42:778-780.

9. Crispi S, Piccolo MT, D'Avino A, Donizetti A, Viceconte R, Spyrou M, Calogero RA, Baldi A, Signorile PG: Transcriptional profiling of endometriosis tissues identifies genes related to organogenesis defects. J Cell Physiol 2013, 228:1927-1934.

10. La Marca A, Broekmans FJ, Volpe A, Fauser BC, Macklon NS, ESHRE Special Interest Group for Reproductive Endocrinology-AMH Round Table: Anti-Mullerian hormone (AMH): what do we still need to know? Hum Reproduct 2009, 24:2264-2275.

11. Tal $R$, Seifer DB: Potential mechanisms for racial and ethnic differences in antimüllerian hormone and ovarian reserve. Int J Endocrinol 2013, 2013:818912.

12. Wang J, Dicken C, Lustbader JW, Tortoriello DV: Evidence for a Mullerianinhibiting substance autocrine/paracrine system in adult human endometrium. Fertil Steril 2009, 91:1195-1203.

13. Boccellino M, Quagliuolo L, Verde A, La Porta R, Crispi S, Piccolo MT, Vitiello A, Baldi A, Signorile PG: In vitro model of stromal and epithelial immortalized endometriotic cells. J Cell Biochem 2012, 113:1292-1301.

14. Pepinsky RB, Sinclair LK, Chow EP, Mattaliano RJ, Manganaro TF, Donahoe PK, Cate RL: Proteolytic processing of mullerian inhibiting substance produces a transforming growth factor-beta-like fragment. J Biol Chem 1988, 263:18961-18964.

15. Grossman MP, Nakajima ST, Fallat ME, Siow Y: Mullerian-inhibiting substance inhibits cytochrome P450 aromatase activity in human granulosa lutein cell culture. Fertil Steril 2008, 89:1364-1370.

16. Nebbioso A, Clarke N, Voltz E, Germain E, Ambrosino C, Bontempo P, Alvarez R, Schiavone EM, Ferrara F, Bresciani F, Weisz A, de Lera AR, Gronemeyer $\mathrm{H}$, Altucci L: Tumor-selective action of HDAC inhibitors involves TRAIL induction in acute myeloid leukemia cells. Nat Med 2005 $11: 77-84$

17. Giudice LC, Kao LC: Endometriosis. Lancet 2004, 364:1789-1799.

18. Bruner-Tran KL, Osteen KG, Taylor HS, Sokalska A, Haines K, Duleba AJ: Resveratrol inhibits development of experimental endometriosis in vivo and reduces endometrial stromal cell invasiveness in vitro. Biol Reprod 2011, 84:106-112.

19. Pitsos $M$, Kanakas $\mathrm{N}$ : The role of matrix metalloproteinases in the pathogenesis of endometriosis. Reprod Sci 2009, 16:717-726.

20. Nezhat FR, Pejovic T, Reis FM, Guo SW: The link between endometriosis and ovarian cancer: clinical implications. Int J Gynecol Cancer 2014, 24:623-628.

21. Melin A, Sparen P, Bergqvist A: Endometriosis and the risk of cancer with special emphasis on ovarian cancer. Hum Reprod 2006, 21:1237-1242.

22. Hornstein MD, Thomas PP, Sober AJ, Wyshak G, Albright NL, Frisch RE: Association between endometriosis, dysplastic nevi and history of melanoma in women of reproductive age. Human Reprod 1997, 1997(12):143-145.

23. Bertelsen L, Mellemkjer L, Frederiksen K, Kyer SK, Brinton LA, Sakoda LC, van Valkengoed I, Olsen $J H$ : Risk for breast cancer among women with endometriosis. Int J Cancer 2007, 120:1372-1375.

24. Varma R, Rollason T, Gupta JK, Maher ER: Endometriosis and the neoplastic process. Reproduction 2004, 127:293-304.

25. Durlinger ALL, Gruijters MJG, Kramer P, Karels B, Ingraham HA, Nachtigal MW, Uilenbroek JT, Grootegoed JA, Themmen AP: Anti-Mullerian hormone inhibits initiation of primordial follicle growth in the mouse ovary. Endocrinology 2002, 143:3836-3844

26. Visser JA, Schipper I, Laven JS, Themmen AP: Anti-Müllerian hormone: an ovarian reserve marker in primary ovarian insufficiency. Nat Rev Endocrinol 2012, 8:331-341.

27. Renaud EJ, MacLaughlin DT, Oliva E, Rueda BR, Donahoe PK: Endometrial cancer is a receptor-mediated target for Mullerian inihibiting substance. Proc Natl Acad Sci U S A 2005, 102:111-116.

28. Stephen AE, Pearsall LA, Christian BP, Donahoe PK, Vacanti JP, MacLaughlin DT: Highly purified müllerian inhibiting substance inhibits human ovarian cancer in vivo. Clin Cancer Res 2002, 8:2640-2646.

29. Wei X, Dombkowski D, Meirelles K, Pieretti-Vanmarcke R, Szotek PP, Chang HL, Preffer Fl, Mueller PR, Teixeira J, MacLaughlin DT, Donahoe PK: Mullerian inhibiting substance preferentially inhibits stem/progenitors in human ovarian cancer cell lines compared with chemotherapeutics. Proc Natl Acad Sci U S A 2010, 107:18874-18879.

30. Chang HL, Pieretti-Vanmarcke R, Nicolaou F, Li X, Wei X, MacLaughlin DT, Donahoe PK: Mullerian inhibiting substance inhibits invasion and migration of epithelial cancer cell lines. Gynecol Oncol 2011, 120:128-134.

31. Bakkum-Gamez JN, Aletti G, Lewis KA, Keeney GL, Thomas BM, NavarroTeulon I, Cliby WA: Mullerian inhibiting substance tyoe II receptor (MISIIR): a novel tissue-specific target expressed by gynecologic cancers. Gynecol Oncol 2008, 108:141-148.

32. Namkung J, Song JY, Jo HH, Kim MR, Lew YO, Donahoe PK, MacLaughlin DT, Kim JH: Mullerian inhibiting substance induces apoptosis of human endometrial stromal cells in endometriosis. J Clin Endocrinol Metab 2012, 97:3224-3230

33. Borahay MA, Lu F, Ozpolat B, Tekedereli I, Gurates B, Karipcin S, Kilic GS: Mullerian inhibiting substance suppresses proliferation and induces apoptosis and autophagy in endometriosis cells in vitro. ISRN Obstet Gynecol 2013, 2013:361489.

34. Pépin D, Hoang M, Nicolaou F, Hendren K, Benedict LA, Al-Moujahed A, Sosulski A, Marmalidou A, Vavvas D, Donahoe PK: An albumin leader sequence coupled with a cleavage site modification enhances the yield of recombinant C-terminal Mullerian Inhibiting Substance. Technology 2013, 1:63-71.

35. Rey R, Lukas-Croisier C, Lasala C, Bedecarrás P: AMH/MIS: what we know already about the gene, the protein and its regulation. Mol Cell Endocrinol 2003, 211:21-31.

36. di Clemente N, Jamin SP, Lugovskoy A, Carmillo P, Ehrenfels C, Picard JY Whitty A, Josso N, Pepinsky RB, Cate RL: Processing of anti-mullerian hormone regulates receptor activation by a mechanism distinct from TGF- $\beta$. Mol Endocrinol 2010, 24:2193-2206.

37. Attar E, Bulun SE: Aromatase and other steroidogenic genes in endometriosis: translational aspects. Hum Reprod Update 2006, 12:49-56.

38. Simpson ER, Clyne C, Rubin G, Boon WC, Robertson K, Britt K, Speed C, Jones M: Aromatase-a brief overview. Annu Rev Physiol 2002, 64:93-127.

\section{doi:10.1186/1756-9966-33-46}

Cite this article as: Signorile et al:: Anti-mullerian hormone is expressed by endometriosis tissues and induces cell cycle arrest and apoptosis in endometriosis cells. Journal of Experimental \& Clinical Cancer Research 2014 33:46

\section{Submit your next manuscript to BioMed Central and take full advantage of:}

- Convenient online submission

- Thorough peer review

- No space constraints or color figure charges

- Immediate publication on acceptance

- Inclusion in PubMed, CAS, Scopus and Google Scholar

- Research which is freely available for redistribution 